\title{
Sloveenia folkloristika ja etnoloogia 2
}

\author{
Mare Kõiva, Andres Kuperjanov
}

\begin{abstract}
Teesid
Ülevaade tutvustab Sloveenia Teaduste Akadeemia etnoloogia, folkloristika ja visuaalse antropoloogia uurimiskeskusi, uurijaid ja publikatsioone. Lähemalt vaadeldakse sloveeni folkloristika alusepanija Karel Štrekelj rahvaluule kogumise ja publitseerimise põhimõtteid. Tutvustatakse tänaste uurijate Monika Kropej, Jurij Fikfaki ja Naško Križnari uurimisvaldkondi ning Blaž Telbani rahvakunstigaleriid Skrina.
\end{abstract}

Märksõnad: etnoloogia, folkloristika, folklooriväljaanded, Sloveenia

Päikesest soojaks köetud kesklinna tänavakohvikuis looklevad kepica sladoleda ehk jäätise arusaamatult pikad järjekorrad saadavad hommikusi rännakuid etnoloogiainstituuti ja õhtusi teekondi sealt tagasi ega kao ka hilisõhtul kuhugi. Järjekorrad on nii veenvalt pikad, konkureerivad kuulsate Ljubljana lohede ja rooma varemetega, et iga päevaga müütilisem maius jääbki proovimata. Rändame õhtuti vanalinnas, tõuseme tähetorni mäele, kus jooksutatakse koeri ja ennast - see on linna serva roheline pöögimetsamaastik -, kuulame kesklinna kirikus harrastuskoori, tõuseme eelajaloolisele asustusalale ehitatud Ljubljana lossini.

Arvatavasti 9. sajandil rajatud ning 1141. aastast kirjalikes allikais märgitud kindlust on alates 16. sajandist mitmel korral tuntud arhitektide poolt ümber kujundatud ja sajandeid linna vanglahoonena kasutatud. 1905. aastast on mäel kõrguv ehitis aga linna kultuurikeskus, mida on umbkaudu samast ajast alates rekonstrueeritud. Praegu areneb lossis riigi ametlike kontsertide ja kunstinäituste kõrval (rahva)kunstikaubandus turistidele ning kasvab turismi ja meelelahutustööstuse osana kohvikute jm vaba aja veetmise paikade hulk. Nagu teisteski Sloveenia lossides on võimalik seal abielluda keskaegsete kostüümide ja etendusega ning kasutada erilisi pulmatube.

Närveldavaid rüütleid ja pruutneitseid, kes ootavad pruutpaari saabumist, kohtame Ljubljanast vanema, Predjama lossi juures, mis lisaks harukordsele asendile ja arvukatele legendidele teenibki keskaegsete turniiride ja pulmade etendamisega. Legendi järgi alistus vankumatu kindlus, mis pidas pikaaegsele piiramisele vastu

http://haldjas.folklore.ee/tagused/nr28/sloveenia.pdf 


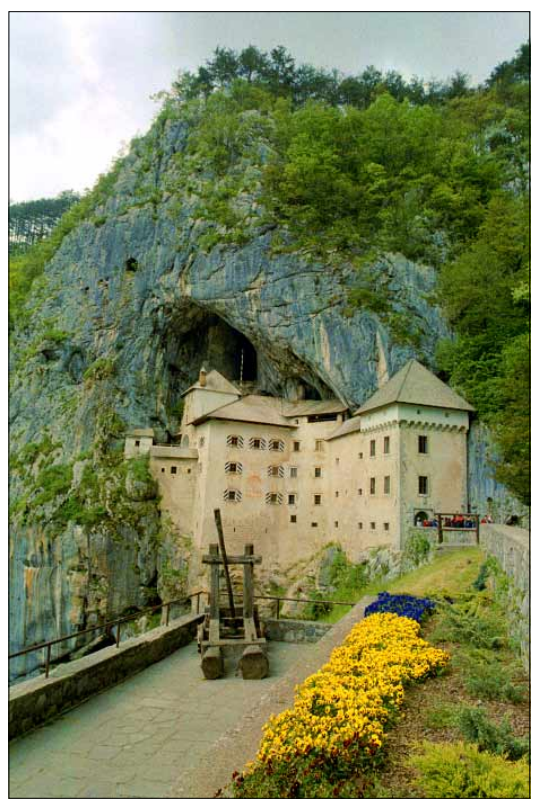

Predjama lossi sisemuses peitub iidne arheoloogiamälestis, tänapäeval on kaunis ehitis muuseum, mille ruume kasutatakse keskaegsete pulmade pidamiseks, ümbrust etendusteks ja rollimängudeks.
Mare Kõiva, Andres Kuperjanov

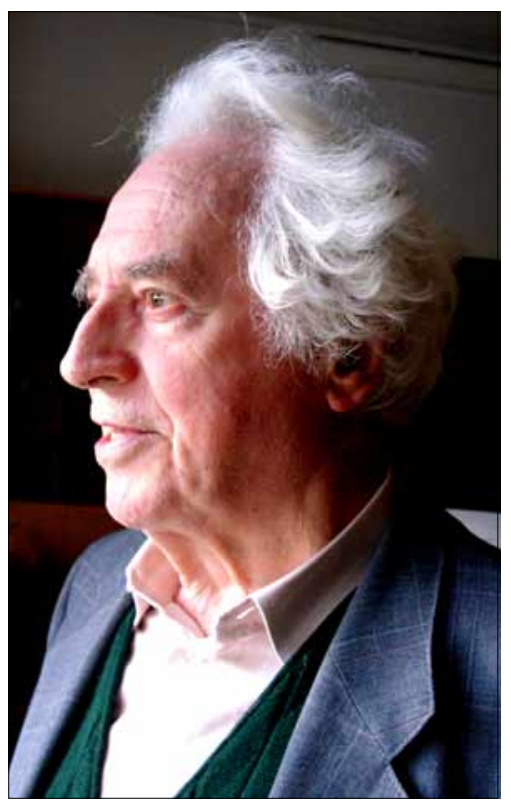

Akadeemik Milko Matičetov arutleb pseudoteaduslike keeleteooriate üle.

Andres Kuperjanovi fotod 2004.

tänu lossi kavalale veekogumissüsteemile ja salakäikude kaudu hangitud toidule, kuni vaenlane läkitas pommi otse harjumuspäraselt käimlas mõtiskleva kindluseülema pihta.

Keskaegseid pulmi imiteerivad lossipulmad on folkloori jätkuelu ilming ja osake tänase folkloristika jäädvustamis- ja analüüsimisalast, õigupoolest protsess, kus taaselustatakse rituaale, kalendripühi, toitumistavasid, rõivastust. Tulenevad sellised etendused lokaalsuse loomise ja väljendamise vajadusest, ajastukohasest vanade tavade väärtustamisest või uusaegsest kultuuriväärtuste kaubastamisest, on omaette küsimus. Paljud taaselustatud nähtused on seotud keskaja ja rollimängude populaarsuse, samuti vajadusega kordumatute elusündmuste järele.

Sloveenia trükitud raamatute ajalugu algab 16. sajandi keskpaigast - esimene trükis pärineb aastast 1550. Seevastu käsikirja- 
lised raamatud pärinevad 9. sajandist. Ljubljana rahvusraamatukogus ongi olulise tähtpäeva puhul avatud vanimate sloveenikeelsete käsikirjade näitus. Unikaalne väljapanek on koostatud Austria, Itaalia, Saksamaa ja Sloveenia kollektsioonide põhjal. Esimest korda ajaloo jooksul on käsikirjad koondatud samasse saali ja seda põhjusel, et Freisingi kolme käsikirja (vanimad teadaolevad sloveenikeelsed tekstid) autori piiskop Abrahami surmast möödus 26. mail 2004 tuhat aastat. Paljusid hinnalisi keskaja tekste ja nende tõlkeid saab lugeda internetist, sest tollaste kirjatööde digitaliseerimine on olnud üksikuurijate, projektide ja institutsioonide südameasjaks. Näiteks on Freisingi käsikirjadest valmistanud digitaalraamatu Leideni ülikooli võrdleva keeleteaduse professor Frederik Kortland (http://www.kortlandt.nl/editions/freis.html).

Näitusekülastajad loevad formaadilt, stiililt ja kujunduselt erisuguste raamatute valitud lehekülgi ning jälgivad giidi abiga ortograafia ja stiili erisusi. Hapra paberi säilimine muutlikus ja püsimatus maailmas loob tavatu ülendatud kindlustunde tänases päevas. Väljume liigutatult, järgmise rühma elev kohtumisootus vastu vaatamas.

Etnoloogiainstituudi kolmanda korruse ruumides, otse uurijate kabinettide naabruses paiknevad rahvaluule käsikirjade arhiiv ja erialaraamatukogu. Korrus allpool asub Teaduste Akadeemia raamatukogu, mille lahket abi kasutame ülevaate saamiseks perioodikast ja erialakirjandusest. Sloveeni ja lääneslaavi väljaannete, meile tavaliselt kättesaamatute raamatute kõrval on hea valik ka saksa ja naaberalade kirjandusest. Et akadeemia asutustel on oma erialaraamatukogud, mis kajastuvad ühtses elektronkataloogis, saab tellida ja kasutada näiteks Maribori ülikooli ja mõistagi erinevate Ljubljana instituutide raamatukogusid. Meie meelest on siin uurimiseks maksimaalselt mõnus keskkond, millele viitab asjaolu, et pensioneerunud etnolooge ja folkloriste kohtab instituudis sama sageli kui doktorante.

Üks sagedastest külalistest on akadeemik Milko Matičetov, $E n$ zyclopädie des Märchensi kaastööline, kelle viimase aja huvide hulka kuuluvad keelesuguluse hüpoteeside loojad. Ta on tuttav ka Georg Truusmani kirjutiste ja ideedega. Jah, kütkestav teema. Tutvustame omalt poolt Karl August Hermanni ja Jüri Härmatare ideid sugulusest sumeritega, pikka aega GULAGi laagrites ja Norilskis viibinud saarlase teooriat sugulusest foiniiklastega ja nõukogude ajal ringelnud arutluskäike sugulusest polüneeslaste, baskide, ainu- 
de ja paljude teiste põliste rahvastega. M. Matičetov on pidanud kirjavahetust näiteks Oskar Looritsaga muinasjuttudele eesti paralleelide leidmiseks ja toob ühel visiitidest kaasa eesti folkloristi vastuse. Teeme sellest koopia. Sellised ootamatud passumid liigutavad alati sügavalt.

Sloveeni folkloorikogu varasemad üleskirjutused pärinevad 19. sajandist. Kogujate kaupa mappidesse süstematiseeritud käsikirjad sisaldavad folkloori kõrval muudki pärimusainest. Komenis sündinud folkloori kogumise suurkuju Karel Štrekelj (1859-1912)

\section{upprala, 28. XII $\mathrm{SO}^{-}$}

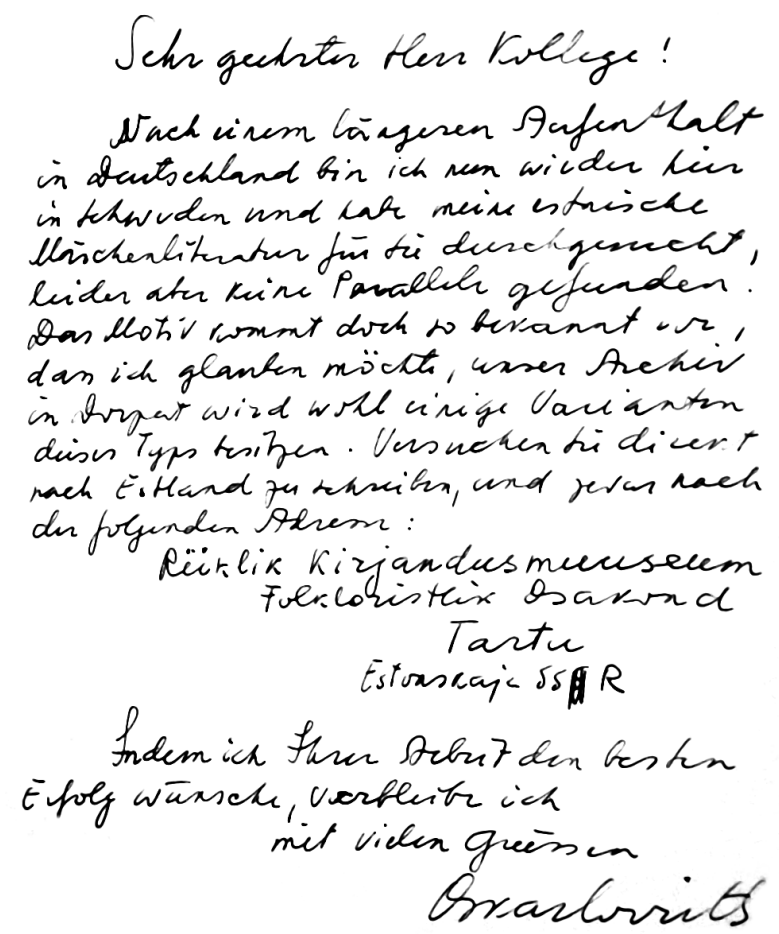

Oskar Looritsa vastus sloveeni erialakaaslasele. Vahetult enne Teist maailmasõda kasutas ta nimetust rahvaluule kõrval nimetust folkloristika. 
veetis märkimisväärse osa oma töisest elust Austrias, kus ta suri tunnustatud keeleteadlase, slaavi etnoloogia ja folkloristika lektori ning eksperdina. Lingvistina oli ta mõjutatud Jan Niecisław Ignacy Baudouin de Courtenayst (1845-1929) ja oma kaasaegsetest slaavi filoloogidest, folkloristina omas tihedaid sidemeid Jirí (Georg) Polívka (1858-1933) ja teiste uurijatega, oli kursis uusimate saksakeelsete käsitlustega. On tähelepanuväärne, et ta rajas 1887. aastal, valituna sloveeni rahvalauluväljaande toimetajaks, kaastööliste võrgu, kuhu kuulus üle maa 243 kaastöölist. Tema kogumismeetod, sedastab Monika Kropej monograafias Karel Śtrekelj - iz vrelcev besedne ustvarjalnosti (Karel Štrekelj - luule allikast; Ljubljana 2001), lähtus ajaloolise antropoloogia laiahaardelisusest. Kogumise algusest esimese köite avaldamiseni 1895. aastal kulus umbkaudu kaheksa aastat. Ilmuda jõudnud seitsme lauluköite varjamatult rustikaalse ja paiguti erootilise sisu ümber puhkes omal ajal kirglik vaidlus, sest tekstid erinesid tollasest romantilisest rahva ja rahvaluule kontseptsioonist täielikult, editsioon aga pälvis rahvusvahelise heakskiidu. Väljaandes esitatud liigitus ja laulude kommentaarid kehtivad tänini, samuti on editeerimisel jätkuvalt eeskujuks tema koostatud täpsed registrid ja kõigiti tasemel teadusaparatuur. Monika Kropej sõnutsi põhineb sealne laulude liigitus tollal üldiselt tunnustatud viisil jagada laulud algupärasteks rahvalauludeks ja rahvalikeks lauludeks. Nagu eespool viidatud, oli K. Štrekelj hästi lõimunud toonaste juhtivate slaavi filoloogidega ning nende seas tunnustatud teadlane.

Kui võrrelda sloveeni suurmeest eesti rahvaluule suurkuju Jakob Hurdaga (1839-1907), siis on sarnast ja erinevat küllaga, alates sellest, et mõlemad olid keeleteadlased, sel alal doktorikraadi omandanud ja sisuliselt kaasaegsed. Jakob Hurda mastaapne rahvaluulekogumisalane kihutustöö ja ajalehtedes avaldatud aruanded kohalike kirjasaatjate tööst kandsid koguselt suurema vilja - eesti rahvaluule suurkogujale saadeti üle saja tuhande lehekülje väga mitmesugust materjali, lisaks kogusid umbes samal ajal rahvaluulet teisedki eestlased. Peaaegu samast ajast pärineva, kuid mõnevõrra teistele rahvaluuleliikidele orienteeritud Matthias Johann Eiseni (1857-1934) kogu sisaldab näiteks üle 90000 lehekülje pärimust. Jakob Hurda eesti vanade rahvalaulude kihelkondlik väljannete seeria piirdus viie mahuka raamatuga, kuid rajas samuti aluse eesti rahvalaulude liigitamis- ja editeerimistavadele. Tema laiahaardeline rahvaluule käsitlus mõjutas edaspidist kogumistraditsiooni. 
J. Hurda unistuseks oli koostada kogutu põhjal eestlaste oma ajalugu, sellele ideele resoneerinud kohalikud kirjasaatjad püüdsid sellist ainest leida, kuid ka ise luua.

Suurim erinevus peitub aga kahe mehe ametis ja ajakasutamise võimalustes. Kui sloveeni teadlane oli 19. sajandil Grazi ülikooli korraline lektor, luges sloveeni keele ja kirjanduse ning mitmeid rahvaluulekursusi, seljataga Viini seaduste tõlkimine sloveeni keelde, siis Jakob Hurt teenis leiba pastorina. Tema ajast pidi lisaks ametitööle ja priitahtlikule rahvaluulega tegelemisele jätkuma teaduseks, eestikeelse Aleksandrikooli asutamiskomitee koosolekuteks ja paljudeks muudeks rahvusliku liikumise igapäevasteks toiminguteks, ideede genereerimiseks ja ausalt üteldes ka vaimunüristavaks jagelemiseks rahvusliku liikumise paiguti vastuolulise vene- ja saksameelse seltskonnaga.

Sloveenist suurmehe kaaskondlased olid teadlased, ta tugines Euroopa mõttekaaslastest õpetlaste seisukohtadele, tegeles paleograafia, kirikuslaavi keele, serbo-horvaadi kirjanduse ja muude huviväärsete või loengukursustega seotud aladega. Kui 1903. aastal asutati Matija Murko (1861-1951) õhutusel Sloveenia Ajaloo Selts, asus see tegelema mh etnograafiaga. Toonaste filosoofiliste vaadete järgi kandis ajalooseltsi väljaanne loomulikult nimetust Ajaloo ja Etnograafia Ajakiri. Umbkaudu seltsi rajamisega samal aastal alustas K. Štrekelj uue suure tööga - Austria rahvalaulude (13. sajandist alates kuulus Sloveenia Hapsburgidele) peatoimetajana asus ta koostama rahvalaulude suurväljaande põhimõtteid, kusjuures ta kavatses rahvalaulud publitseerida koos viisidega. Juhend rahvalaulude, rahvamuusika, rahvatantsude ja kombestiku kogumiseks sisaldas ühtlasi tehnilisi nõuandeid kõigi nimetatud liikide jäädvustamiseks. Lisaandmete kogumiseks levitas ta kohalike kaastööliste seas 17 küsimusega küsitluskava. Mõistagi tähendas see igapäevast suhtlemist kaastöölistega ja pidevat visa tööd.

Jakob Hurda monumentaalsed setu rahvalaulude väljaanded ilmusid alates 1903. aastast, kuid enamik ta kavandatust jäi täitumatuks unistuseks samuti nagu ka enamus sloveeni aatekaaslase kavatsustest - näiteks jäi järeltulevate põlvede lõpetada sloveeni muinasjuttude väljaanne. Ajastukohase moevälimuse juurde kuulunud vuntsid ja habe muudavad need erineva saatusega mehed väliseltki veidi sarnaseks.

Etnoloogiainstituudis on meie igapäevane nõuandja Monika Kropej, Mythologia Slavica toimetaja. Oleme teda kohanud nii klassi- 


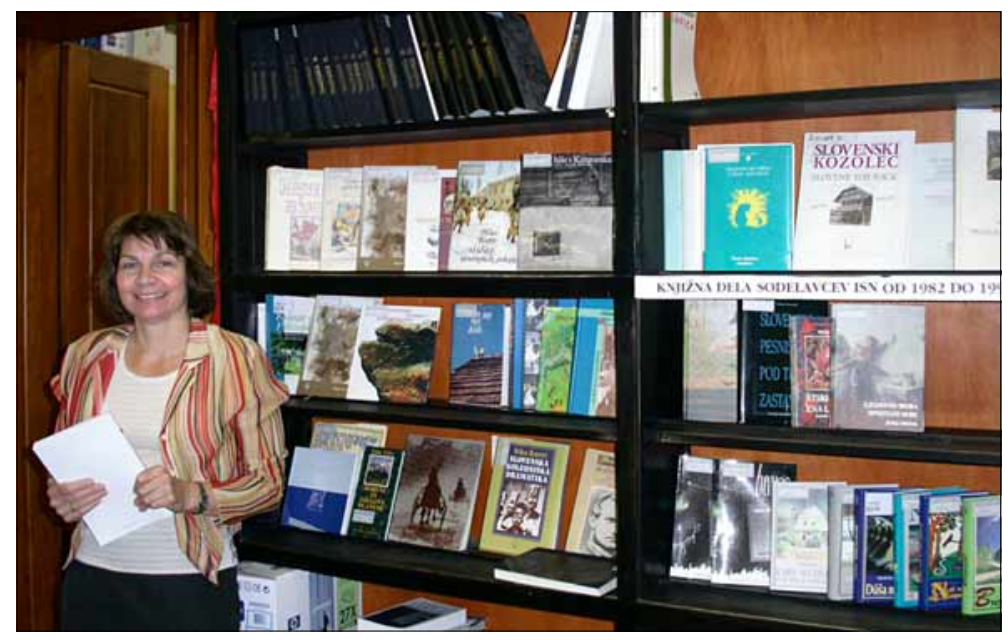

Monika Kropej etnoloogiainstituudi uudisraamatuid tutvustamas. Andres Kuperjanovi foto 2004.

kalise kui ka kaasaegse pärimuse foorumitel. Kuigi administratiivset ja toimetajatööd on uurimistööga keerukas kombineerida, on ta sellega ometi edukalt hakkama saanud. 19. sajandi folkloristika ja Karel Štrekelj pärand on üks paljudest huvidest näiteks sloveeni loitsude (vt nt http://www.folklore.ee/folklore/vol24/slovcharm.pdf), karstilugude, kaasaegse ja klassikalise jutupärimuse erinevate aspektide, uskumuste ja mütoloogia kõrval. Parajasti pooleliolevat sloveeni mütoloogia käsikirja toetavad varasemad käsitlused rahvajuttude deemonlikest olenditest. Sloveeni üliõpilaste jutupärimust käsitleb M. Kropej vastavasisuline artikkel (http://users.aber.ac.uk/ mikstaff/ftn56.htm); akadeemiliste uurimuste kõrval on ta koostanud laiemale lugejaskonnale suunatud tekstivalimikke, millest oli juttu eelmises osas.

Ka Jurij Fikfakiga oleme kohtunud aastate vältel erinevatel foorumitel. SIEFi (Société Internationale d'Ethnologie et de Folklore = Rahvusvaheline Etnoloogide ja Folkloristide Selts) 2004. aasta Marseille' kongressil Among others tutvustas ta Sloveenia astumist Euroopa Liitu ja sellega seotud rituaale, kuid ühtlasi ka noorte väikesi äärmusrühmitusi. Esimene visiit J. Fikfaki kabinetti ja paljalt tema monitori nägemine ajas kadedusest roheliseks ja meenutas taas meediauudist sloveenide IT-edust. Nõukogude Liitu kuulumine 


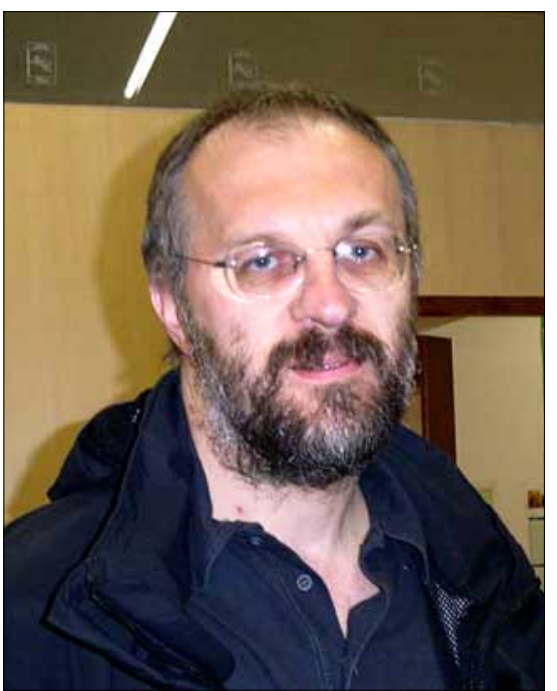

Jurij Fikfaki huvitavad etnoloogia ja folkloristika teoreetilised küsimused. Andres Kuperjanovi foto 2004. looteaduses (Digital Image Processing in History, 1993) ja interaktiivsed väljundid - rituaale või kindlat piirkonda tutvustavate publikatsioonide loomulik komponent - esindavad tema sellealaseid huvisid. Viimastel kümnenditel on ta tegelnud rahvuse reflekteerumise ja identiteetide konstrueerimise küsimustega. Näiteks käsitleb ta uusimas etnograafiainstituudi kogumikus Qualitative Research:Different Perspectives, Emerging Trends (kaastoimetajad Frane Adam ja Detlef Graz) teemat etnograafiast autoetnograafiani, jätkates 19. sajandi teise poole ning uuema folkloristika ja etnoloogia arengutendentside iseloomustamist.

SIEFi 2004. aasta kongressil vaatles üks Sloveeniat esindavatest teadlastest, kuidas tutvutab sloveene tänane globaalselt tuntud menukirjanik. Tuleb tunnistada, et selles on palju sarnast varasemate sajandite õpetlaste viisile teist ja võorast iseloomustada. Jurij Fikfak on näiteks osutanud, et ajastuomane filosoofia mõjutab tugevasti teiste, eriti aga nn tsiviliseerimatute hulka liigitatud kultuuride kujutamist, selliselt määratletud rahvaste ja kultuurinähtuste jäädvustamist ja tõlgendamist. Lähtematerjalina on ta ka- 
sutanud valgustusajastu ideedest mõjutatud mitmekülgse teadlase, Euroopa Teaduste Akadeemia liikme Balthasar Hacqueti (17391815) teost Abbildung und Beschreibung der südwest- und östlichen Wenden, Illyrer und Slaven, deren geographische Ausbreitung von dem Adriatischen Meere bis an den Ponto, deren Sitten, Gebräuche, Handthierung, Gewerbe, Religion u.s.w. nach einer zehnjährigen Reise und vierzigjährigen Aufenthalte in jenen Gegenden I-V (Leipzig 18011808) ja seal trükitud sloveenide, horvaatide ja teiste "metslastest" väikerahvaste etnograafilisi kirjeldusi (vt http://www.zrc-sazu.si/isn/ Publikacije/FikfakHacquet.pdf).

Sloveenia etnoloogid ja folkloristid on tänapäeval lõimunud erinevate uurimisvõrgustike ja -keskustega. Klassikalise folkloori kõrval jälgitakse täna ja praegu meeli köitvaid teemasid, aktuaalne on 19. sajandi suundade taastõlgendamine ja nüüdisfolkloristika koolkonnad. Väikese rahva teadlased on olude sunnil laiahaardelised ja mitmekülgsed nagu nende kolleegid 19. sajandil. Väljaannete ja uurimistööde osas tehakse koostööd naaberteaduste ja lähimaadega. Heaks näiteks sisemaisest koostööst on maskeerimisprojekt, mille abil hinnati maskikombestiku nüüdisseisundit kogu maal, kuhu olid kaasatud erinevate keskuste etnoloogid ja museoloogid, väljundiks kogumik (http://www.folklore.ee/tagused/nr27/mare.htm), arvukalt dokumenteerivaid fotosid ja videoülesvõtteid.

Etnoloogiainstituudi juurde kuuluva audiovisuaalse keskuse juhataja Naško Križnar tervitas meid esmakohtumisel küsimusega, kas oleme käinud Pärnu visuaalse antropoloogia festivalil. Võisime taas tõdeda, et arvatavasti on kõigil esimestest üritustest osavõtjail sellest helged mälestused. Audiovisuaalse keskuse pilgeni tehnifitseeritud ruumid asuvad instituudist mõne maja võrra eemal. Keskuse kaastöölised käivad korrapäraselt välitöil, osa materjalist vormistatakse kohe erineva otstarbega etnograafilisteks filmideks, osa neist jääbki kindlaid piirkondi ja protsesse jäädvustavaks toormaterjaliks. Lõppkokkuvõttes nõuab töö säärases keskuses entusiasmi ja oskusi, sest nappide vahenditega tuleb jäädvustada komplitseeritud ainest, töötada äärmuslikes oludes, luua elavaid pilte staatilisest ainesest.

Parasjagu jookseb keskuse videomakis film vaesemate perede elust jugoslaavia ajal (1960. aastad) - alasti dokumendis kujutatu sarnaneb veetilgana Eesti agulikorterite olustikule. On ka erinevat, kuid selle mustri kindlakstegemine vajaks pikemat süvenemisaega, eelistame arhailiste töövõtete visualiseeringuid. Festivalide 
juurde tagasi tulles: audiovisuaalse keskuse suvekoolist võtavad osa erinevate Euroopa kõrgkoolide õppurid (loodetavasti jõuab mõni eestlanegi sinna) ja instituudi veebilehel on avaldatud filmograafia nimestik (http://www.zrc-sazu.si/isn/avdiovizualnilab.htm). Naško Križnar on nii visuaalse antropoloogia kui ka rituaalide teemal üpris palju kirjutanud. Praktiku ja teoreetiku sümbioos on humanitaarsele asutusele erakordne õnn, kuid uurimises ja visuaalses kunstis võrdväärselt oskuslikul inimesel on tavafolkloristi või -etnoloogiga võrreldes eelisseisund veel põhjusel, et ta valdab professionaalselt visuaalset kirjaoskust. Jäädvustustehnika lihtsustumisega on ju igamehe fotosid, filme ja montaaže aina rohkem. Seetõttu on tavaline olukord, kus unikaalsest sündmusest osasaanuna mõistad, et kogu ilu jäi su enda silmadesse, sest masinavärgile ei ole keegi suutnud selgeks teha, mis peab kaadrisse jääma.

Külastasime ka Ljubljana ülikooli etnoloogia ja kultuuriantropoloogia õppetooli, mille loengukava sarnaneb (balkanistika ja slavistika erikursused välja arvatud) teiste Euroopa kõrgkoolide omale. Õppetoolil on sidemeid paljude keskustega, sh Halle Max Plancki Sotsiaalantropoloogia Instituudiga. Ljubljana ülikooli etnoloogid on pikka aega näiteks korraldanud välitöid Aafrikas ja Ida-Euroopas ning nende uurimisteemad ulatuvad punkmuusikast traditsiooniliste folkloorikäsitlusteni, nagu Mirjam Mencej monograafia huntide peremehest, artiklid veest ja tulest slaavi mütoloogias. Õppetooli väljaannete seerias avaldatakse monograafiaid, artikleid ja MESSi (Keskeuroopa Etnoloogide suvekool) ettekandeid. Kuna suvekooli reegliks on, et üks isik saab esineda üksnes ühe korra ja arutluse all on aktuaalsed suundumused, siis puudutavad artiklid rahvuse, kultuurilise omandi, maastiku, ruumi, mütoloogia, narratiivide, muuseumide ja muid teemasid.

Tutvusime veel arheoloogiainstituudi digitaalsete kaartide projekti ja andmebaasidega - muljetavaldavad olid nii sisekasutajale mõeldud lahendused kui ka veebiväljundid.

Juba Ljubljana lennujaama vaateaknaid täitsid sloveeni rahvusliku kunsti ja käsitöö näidised, sh soojatoonilised humoristlike muinasjutumotiividega või talupojaelu ainetel loodud lubokid. Siis me veel ei teadnud, et neist mõne autori ja paljude kaubastajaga kohtume lähipäevil. Blaž Telbani (hariduselt kultuuriantropoloog) kunstigaleriis Skrina imetlesime korduvalt vaimukaid või lihtsalt kauneid maale, ehteid, keraamikat, lubokki, käsitöid. Blaži galerii ja tema isik ühendavad paljusid etnostiili (kuid mitte üksnes) varjun- 


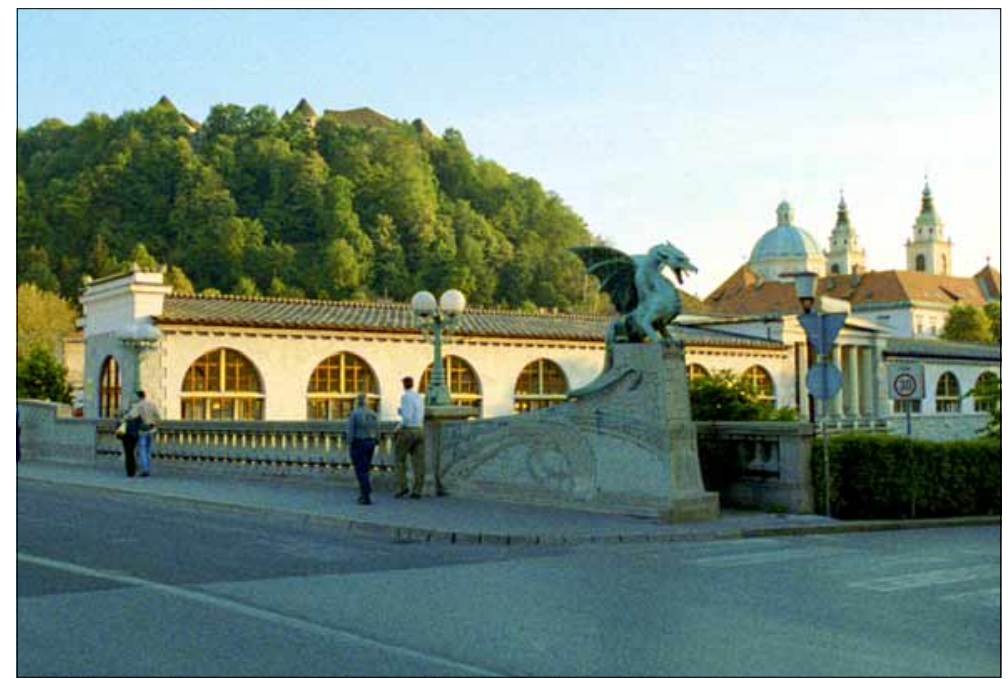

Ljubljana tunnuseks on lohed, mida leiab linna erinevates paikades. Sillalohed on neist kuulsaimad. Andres Kuperjanovi foto 2004.

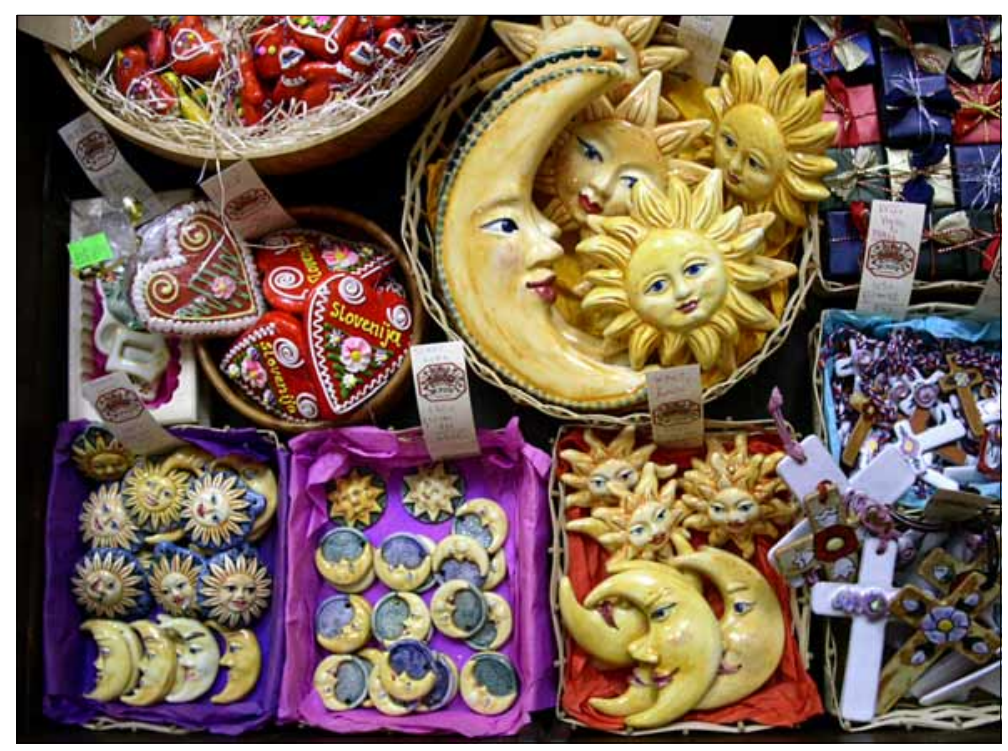

Etnogalerii Skrina sisaldab vaimukat, naljakat, tõsist, õnnetoovat. Andres Kuperjanovi foto 2004. 
diga kunstnikke, ta on rajanud lühikese ajaga UKUga võrreldava rahvakunsti tootva süsteemi. Kultuuriantropoloogina uuris ta indiaanikultuure. Nimelt lahkus ta üliõpilasaastate järel Jugoslaaviast Ameerikasse ja töötas pikki aastaid seal, naasmise järel aga õppejõuna Slobodan Miloševići aegses Belgradis. Segastes diktaatori kukutamise eelsetes keeristes Sloveeniasse naasnuna ei õnnestunud tal erialatööd leida ja nii spetsialiseerus ta ümber (etno)kunstiärile. Tema erahobiks on eri rahvaste toidud - filigraansete teadmiste tõttu oleks ta paremaid toiduantropolooge ja küllap ta selleks ka saab, kui kunstiäri kord rohkem aega jätab.

Keeruline on lühidalt sõnastada igapäevast miljööd, mille loob liikumine rooma müüride ja sammaste vahel või keskaegsetes hoonetes - side ja dialoog lõpmatult pika asustuslooga. Võib-olla see ongi tajutavam mujalt tulnule kui põliselanikule. Vestlesime tunde Monika Kropejga ajakirjade toimetamisest-kirjastamisest, võrdlevast mütoloogiast, rahvaluulest, teaduspoliitikast ja paljust muust. Tõdesime, et kui sarnased ka ei ole ajaloolised olud, mentaalne pärimus ja erialased suundumused, on folkloristika käekäik Euroopas maati vägagi erinev. Sloveenia uus uurijatepõlvkond on toonud uusi teemasid ja meetodeid, kuid jätkatakse ka klassikaliste liikide ja teemadega, erinevatel institutsioonidel on oma nägu, väljakujunenud temaatika, väljaanded, koostöövõrgustikud. Jääb üksnes soovida, et kõik institutsioonid püsiksid jätkuvalt heal järjel.

Töövisiidi õnnestumise eest täname Eesti ja Sloveenia Teaduste Akadeemia välissuhete osakonna lahkeid töötajaid, kolleege Sloveenia Teaduste Akadeemia Etnoloogia Instituudist ja Monika Kropejd. 